\title{
Sampling designs matching species biology produce accurate and affordable abundance indices
}

Wildlife biologists often use grid-based designs to sample animals and generate abundance estimates. Although sampling in grids is theoretically sound, in application, the method can be logistically difficult and expensive when sampling elusive species inhabiting extensive areas. These factors make it challenging to sample animals and meet the statistical assumption of all individuals having an equal probability of capture. Violating this assumption biases results. Does an alternative exist? Perhaps by sampling only where resources attract animals (i.e. targeted sampling), it would provide accurate abundance estimates more efficiently and affordably. However, biases from this approach would also arise if individuals have an unequal probability of capture, especially if some failed to visit the sampling area. Since most biological programs are resource limited, and acquiring abundance data drives many conservation and management applications, it becomes imperative to identify economical and informative sampling designs. Therefore, we evaluated abundance estimates generated from grid and targeted sampling designs using simulations based on geographic positioning system (GPS) data from 42 Alaskan brown bears (Ursus arctos). Migratory salmon drew brown bears from the wider landscape, concentrating them at anadromous streams. This provided a scenario for testing the targeted approach. Grid and targeted sampling varied by trap amount, location (traps placed randomly, systematically or by expert opinion), and traps stationary or moved between capture sessions. We began by identifying when to sample, and if bears had equal probability of capture. We compared abundance estimates against seven criteria: bias, precision, accuracy, effort, plus encounter rates, and probabilities of capture and recapture. One grid (49 km2 cells) and one targeted configuration provided the most accurate results. Both placed traps by expert opinion and moved traps between capture sessions, which raised capture probabilities. The grid design was least biased (-10.5\%), but imprecise (CV 21.2\%), and used most effort (16,100 trap-nights). The targeted configuration was more biased (-17.3\%), but most precise (CV 12.3\%), with least 
effort (7,000 trap-nights). Targeted sampling generated encounter rates four times higher, and capture and recapture probabilities $11 \%$ and $60 \%$ higher than grid sampling, in a sampling frame $88 \%$ smaller. Bears had unequal probability of capture with both sampling designs, partly because some bears never had traps available to sample them. Hence, grid and targeted sampling generated abundance indices, not estimates. Overall, targeted sampling provided the most accurate and affordable design to index abundance. Targeted sampling may offer an alternative method to index the abundance of other species inhabiting expansive and inaccessible landscapes elsewhere, provided their attraction to resource concentrations. 
1 Grant Harris, ${ }^{1}$ United States Fish and Wildlife Service, Albuquerque, NM, 87103, USA

2 Sean Farley, Alaska Department of Fish and Game, 333 Raspberry Road, Anchorage, AK, 399518 , USA.

4 Gareth J. Russell, Department of Mathematical Sciences, New Jersey Institute of Technology, 5 Newark, NJ, 07102, USA.

6 Matthew J. Butler, United States Fish and Wildlife Service, Albuquerque, NM, 87103, USA

7 Jeff Selinger, Alaska Department of Fish and Game, 43961 K-Beach Road, Soldotna, AK 99669, 8 USA.

$9 \quad{ }^{1}$ Corresponding author:

10 United States Fish and Wildlife Service

11 PO Box 1304

12 Albuquerque, NM 87103

13 e-mail: grant_harris@fws.gov

14 phone: 505-248-6817 


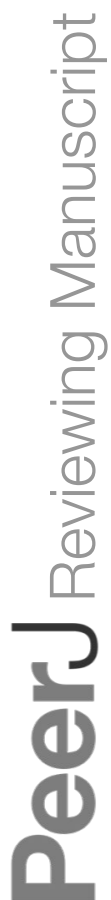

PeerJ reviewing PDF | (v2013:10:892:1:0:NEW 27 Nov 2013) 


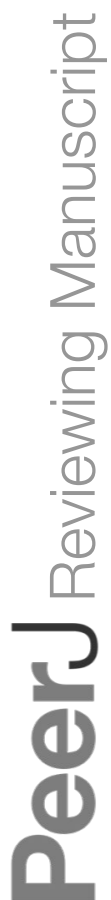

PeerJ reviewing PDF | (v2013:10:892:1:0:NEW 27 Nov 2013) 


\section{INTRODUCTION}

16 Wildlife biologists often rely on photographs or DNA in a capture-mark-recapture (CMR)

17 framework to estimate the abundances of sparsely distributed animals inhabiting expansive,

18 heavily vegetated and inaccessible terrain (Karanth \& Nichols, 1998; Boulanger et al., 2002;

19 Harris et al., 2010; Kindberg et al., 2011). At issue is how to sample effectively and economically under such conditions. In particular, are there alternative sampling designs to the

21 conventional grid?

Grid-based designs operate by enveloping study sites with a uniform cell size and sampling

23 within each cell (e.g. Woods et al., 1999; Poole et al., 2001; Boulanger et al., 2002; Williams et al., 2002; Boulanger et al.,2004; Kendall et al., 2009). Although the approach is popular, grid sampling harbors logistical challenges, and when improperly used, methodological flaws (see below). An alternative sampling design could sample only at biologically important locations that attract the target species (hereafter "targeted sampling"; Karanth \& Nichols, 1998; Sawaya et al., 2012). Obvious resistance to this approach stems from the biases introduced if some individuals

29 in the population failed to visit the sampling area.

30 While abundance estimation forms a cornerstone of wildlife biology, the size of many study sites,

31 challenging terrain and elusiveness of the target species makes acquiring abundance data expensive. Yet most biological programs receive little funding, requiring professionals to pursue 
economical methods to estimate abundance, while maintaining informative and scientifically defensible designs. Given this reality, we evaluated the targeted sampling design by comparing it to conventional grid sampling. If targeted sampling generates abundance estimates affordably and precisely, with low bias and effort, then it could offer an informative and economical alternative to estimating abundances of sparsely distributed animals inhabiting heavily vegetated or topographically complex environments, provided the species attraction to resource concentrations. Globally, many species having these characteristics are of high conservation concern (e.g. Fuller, 1995; Weber \& Rabinowitz, 1996; Shackleton, 1997). Often, abundance data for such species are deficient, unable to inform population status, threat assessments, or provide direction for properly conserving and managing populations of these animals.

\section{Grid and targeted sampling}

Grid sampling aims to ensure that all individuals within the population have the same probability of capture (Nichols \& Karanth, 2002; Williams et al., 2002). While the theory is sound, implementation has at least 3 disadvantages. First, to ensure that all individuals encounter traps, users often scale grid cells to match the average home range size of the target species (Boulanger et al., 2004a; Boulanger et al., 2006). Problems arise when biologists lack home range information for their population under study, home range sizes vary between surveys, or home range sizes vary widely within a population. When home range data are lacking, then practitioners can rely on home range sizes from the same or related species elsewhere, hoping that the cell size used is appropriate (Boulanger et al., 2006; Sawaya et al., 2012). If animals change their behavior in response to concentrated or dispersed resources, making their home ranges shrink or expand, then home range sizes will vary between years (i.e. surveys). This makes it challenging for a defined grid size to always be appropriate. If home range sizes have 
much variation in the population, then a mean value has little biological relevance ( $M c N a b$, 1963; Powell, 2000; Boulanger et al., 2006). By relying on the home range mean, a segment of the population will have home range sizes below the cell size, so traps may not be available to capture them. In each case, using home range data to guide the size of the grid cell may result in the grid being too large, causing an unequal probability of capture. This raises capture heterogeneity, thereby increasing error in the CMR approach (Williams et al., 2002; Boulanger et al., 2004). Since many studies sampling with grid configurations do not biologically justify the grid resolution chosen, they lack information to evaluate this heterogeneity violation (e.g. Woods et al., 1999; Boulanger et al., 2004; Mowat et al., 2005; Boulanger et al., 2008a; Kendall et al., 2008). In any event, for grid sampling, the solution relies on using small cell sizes to ensure that all individuals have a chance of being captured.

Of course, this begs the question of how small cell sizes must be. Although we discuss this point later, it invokes the second issue. Many study sites are large $\left(10,000 \mathrm{~s}\right.$ of $\left.\mathrm{km}^{2}\right)$ and include areas difficult to access, due to vegetation types, terrain, or insecure political situations. Sampling in these areas is logistically difficult or unsafe, and when using small cells sizes, the projects can become prohibitively expensive (Kendall et al., 2009; Harris et al., 2010; Sawaya et al., 2012). A third issue with grid sampling is the same trapping effort covers an entire study area that varies in species densities. This seems inefficient. Overall, these problems risk generating ineffective and expensive sampling designs, which can discourage project implementation (Woods et al., 1999; Boulanger et al., 2002; Kendall et al., 2009). relatively smaller areas. Therefore, places that concentrate important biological resources often contain a high density of the target species (MacArthur, 1972; Karanth et al., 2002). Hence, 
targeted sampling focuses effort in high use areas (places that attract the target animal), which may reduce the amount of area to sample, number of traps, and sampling logistics (e.g. scent marking stations, water holes, trails; Karanth \& Nichols, 1998; Sawaya et al.,2012). Each of these factors lowers project costs. Because the sampling design matches species biology and more animals are sampled in less area, it should increase capture probabilities (Karanth et al., 2002). Further, targeted sampling may facilitate sampling insecure study sites, if the resource concentrations - and hence high densities of the target species - occur in safer areas where they can be sampled.

The estimator would fail if numerous individuals in the population did not frequent the sampling area, or if the proportion that visited changed over time. Then, traps in a targeted configuration would not be available to all individuals equally, in amounts that could vary between surveys, causing bias. This would render the sampling assumptions unreasonable, and the final abundance estimates unreliable (Karanth \& Nichols, 1998, Williams et al., 2002). Further, changes in abundances between years would reflect behavioral responses of the species, or an artifact of sampling design, and not actual variation of the species abundances. The sampling techniques would not generate estimates, but indices. Of course, these are the same issues encountered when sampling animals with grids, when home range sizes vary between surveys, or when cells are too large, so traps fall outside of some animals' home ranges rendering them unavailable for capture.

Our goal is to identify sampling designs that provide accurate, affordable and defensible abundance estimates. Therefore, we compared abundance estimates generated from grid and targeted sampling designs against a known population size. Our evaluations relied on geographic positioning system (GPS) location data from female brown bears (Ursus arctos) inhabiting the Kenai Peninsula of south-central Alaska, USA. Here, migratory salmon drew brown bears from 
102

103

104

105

106

107

108

109

110

111

112

113

114

115

the wider landscape, concentrating them at anadromous streams (i.e. streams containing anadromous fish). This provided a scenario for testing the targeted sampling approach (Miller et al., 1997; Hilderbrand et al., 1999; Boulanger et al., 2004b; Mowat et al., 2005). Because comparisons between designs would be nearly impossible to accomplish in the field, we simulated all sampling in a geographical information system (GIS).

We began by determining the optimal dates to sample. Next, we evaluated if all bears were available for capture during that period. For the targeted scenario, bears must be near streams with anadromous fish. For grids, traps must occur within each bears home range. Therefore, we compared brown bear home range sizes to grid cells of varying extent, to inform the cell sizes used for sampling. For grid and targeted sampling, we sampled during the optimal periods, and evaluated each design against seven criteria: bias, precision and accuracy in the population estimates, effort required to obtain estimates (trap-nights) and encounter rates. We also evaluated capture and recapture probabilities, since the best way to reduce capture heterogeneity is by maximizing them (Lukacs, 2009).

When biologists estimate the abundance of animal populations, their sampling considerations include logistics: the number of traps to deploy, how to place traps, and whether to move traps between capture sessions. Their constraints are time and costs. Therefore, designs with fewer traps and systematic placement are preferable, provided they produce unbiased abundance estimates at the required precision. Similarly, since moving traps between capture sessions adds considerable expense, it makes sense to move traps only if the improvements in accuracy outweigh those costs. Hence, our sampling designs varied by trap amount, location (i.e. traps set randomly, systematically or located by expert opinion), and traps stationary or moved between capture sessions. 


\section{METHODS}

126

127

128

129

130

131

132

133

134

135

136

137

138

139

140

141

142

143

144

\section{Study Area}

We studied brown bears on the Kenai Peninsula, of south-central Alaska, USA $\left(23,310 \mathrm{~km}^{2}\right)$. The western third of the Peninsula consists of thickly forested plains (approximately sea level), while ice fields and precipitous mountains dominate the remaining landscape. Mountains peak at $\approx 2,000 \mathrm{~m}$, and we never sampled areas covered by water or ice (Fig. 1). During summer, schools of anadromous salmon (five species) leave the sea and spawn in the Kenai's freshwater tributaries. These migrating salmon form a resource pulse for brown bears and other wildlife (Hilderbrand et al., 1999).

\section{GPS Telemetry}

Data representing bear movements came from GPS telemetry of female brown bears acquired on the Kenai Peninsula. During 1995 - 2003, the Alaska Department of Fish and Game captured female brown bears throughout the entire Peninsula. Captures occurred in mid-Spring, before deciduous trees leafed and salmon entered streams. Bear captures were geographically dispersed (excluding glaciers) and each bear received a GPS collar. Only females were collared, since males and cubs experience rapid weight gain throughout a season, making the collars either too loose or tight, thereby increasing the risk of injuring (or killing) the bear. All field and capture methods were approved by Alaska Department of Fish and Game, Animal Care and Use Committee, Assurance No. 06-03. GPS collars recorded geographical location, and associated date and time, at intervals ranging from 15 minutes to 13 hours. We only used data with 3-D 
145

146

147

148

149

150

151

152

153

154

155

156

157

accuracy, and resampled these GPS data to 13 hours. Resampling kept the first GPS location for each bear, and each 13-hour fix thereafter. Data for some bears spanned multiple years, generating 51 bear/year combinations. Most data covered 1 June through 30 September of a given year (period of most bear activity, after winter denning).

\section{Trapping Period}

CMR studies often use 4 to 5 sampling sessions (Karanth \& Nichols, 1998; Boulanger et al., 2008a; Boulanger et al., 2008b; Sawaya et al., 2012). We followed this practice, and simulated 5 sessions, each lasting 10 days (50 total days). We determined when to sample by identifying the period between 1 June and 30 September that bears would most likely encounter traps.

We examined 3 approaches to identify the sample period for the grid-based designs. First, we hypothesized that bears leaving dens would explore the landscape and encounter traps. For bears in Alaska, this period began 1 June and ended 20 July. Next, we presumed that greater movements would cause more trap encounters. Therefore, we found the contiguous window of 50 days, when the average movement rate for brown bears between successive GPS fixes was maximized. Lastly, we examined long-range movements by identifying the contiguous window of 50 days that maximized the average distances between the furthest-apart GPS fixes for each bear.

162 To calculate the movement metrics, we divided the 1 June through 30 September period into 10163 day brackets. This generated 122 different intervals (day 1-10, day 2-11, etc.). We then 164 quantified the mean and standard error of brown bear movements in each of the intervals. We 165 retained the 5 contiguous intervals that maximized bear movements ( 50 contiguous days). 
166 The targeted design hinged on salmon being an important food resource that attracted brown

167 bears to anadromous streams (Hilderbrand et al., 1999; Beier, 2005). Therefore, we used the

168 same 122, 10-day intervals to quantify the proportion of GPS fixes $\leq 500 \mathrm{~m}$ of an anadromous

169 stream for each bear. We chose the 5 contiguous 10-day intervals that maximized this proportion.

170 Targeted simulations occurred during those dates.

\section{Availability for Capture}

172 We quantified the sizes of brown bear home ranges, to inform the selection of appropriate cell

173 sizes for the grid-sampling frame. The objective was to ensure that all bears were available for

174 capture. Our method examined the relationships between grid-cell size $(\mathrm{km})$, and the proportion

175 of bears with home range sizes below that cells area. We also calculated the number of traps

176 within each bears home range, to determine if it contained at least one trap. For each bear, home

177 range calculations used GPS data spanning 1 June through 20 July of a given year, to match when

178 grid sampling occurred (see Results). To estimate home range, we used 95\% fixed-kernel and

179 least-squares cross-validation to calculate the smoothing parameter (Hooge \& Eichenlaub, 2000).

180 Data represented home range sizes of different classes of bears (females without cubs, females

181 with cubs of the year, and females with cubs over one year old). In practice, biologists often do

182 not know in advance what classes, or numbers of individuals within those classes would be

183 trapped, so they usually rely on the average home range size to inform the area of the sampling

184 cell (Boulanger et al., 2004a; Boulanger et al., 2006). To test the notion of using an average

185 home range size to inform grid cell area, we averaged the sizes of all home ranges together $(\mathrm{n}=$ 
186

187

188

189

190

191 192 frame $\left(\approx 16,000 \mathrm{~km}^{2}\right)$.

For targeted sampling, we also determined the proportion of bears available for capture. We relied on the GPS data to evaluate if each bear was within $500 \mathrm{~m}$ of an anadromous stream during the sampling period. We then examined the proportion of bears within this sampling frame, for every year of GPS data. The sampling frame was about $3,500 \mathrm{~km}^{2}$, or $22 \%$ of the grid-sampling

\section{Sampling Designs}

194 For grids, we simulated traps in a GIS by dividing the peninsula into 3 sets of square cells, with

195 areas of 49,81 and $121 \mathrm{~km}^{2}$ (Table 1). These cell areas were informed by the home range 196 analysis, and similar cell sizes are often used to estimate brown and grizzly bear population sizes 197 (e.g. Boulanger et al., 2002; Beier et al., 2005; Mowat et al., 2005; Boulanger et al., 2008b;

198 Kendall et al., 2008). Traps were stationary between capture sessions and located using 3

199 different configurations: traps in cell centers, traps placed randomly in the cell, or traps placed by

200 expert opinion in each cell. Expert opinion relied on our knowledge of bear behavior to locate

201 traps (in the GIS) where bears would most likely intercept them, were the traps actually set on the 202 ground. This included locations along streams, ravines and similar topographical features that 203 can attract or funnel moving bears.

204 We simulated the targeted designs using two methods, each with effort (trap-nights) comparable 205 to or less than the grid configurations (Table 1). First, traps were systematically spaced in the 
206

207

208

209

210

211

212

213 224 (separately for grids of 49,81 , and $121 \mathrm{~km}^{2}$; Table 1).

225 For targeted scenarios, we iteratively picked every $5^{\text {th }}$ trap from the set of expertly located traps,

GIS, with 17 and $19 \mathrm{~km}$ spacing. Second, trap locations were identified in the field, by expert opinion. We located these places by ground and plane reconnaissance, based on the characteristics of shallow water or narrow reaches, since these attributes facilitate a bears' ability to catch fish. Trap coordinates were input into the GIS. The traps placed by expert opinion had two configurations that varied by effort.

Previous studies suggested that moving traps between captures sessions increases capture probabilities and the number of individuals captured (Boulanger et al., 2002; Boulanger et al., 2004; Boulanger et al., 2006). This should reduce bias and error in abundance estimates. We tested this advice for brown bears using grid and targeted sampling designs, with traps placed by expert opinion. For grids, we began by simulating 5 different sets of trap locations within each cell. Trap locations were identified with aerial photography of the study area, and the coordinates input into a GIS. We examined 30 scenarios of stationary traps (for each cell size). For five of these scenarios, we held each of the trap sets (sets 1-5) constant across all capture sessions. For the remaining 25 scenarios, we randomly picked a trap in each cell, and held this set constant across all capture sessions (Table 1).

When traps were moved between capture sessions, a different trap set ( 1 of the 5) was used once for each capture session. For example, trap set 3 in capture session 1, then trap set 4 in session 2 , etc. We randomly selected 30 of the 120 possible permutations of moved traps within each cell 226 to ensure a different trap was used each session (140 traps/session). A second configuration of 


\section{Abundance estimation and evaluation}

Lastly, we generated a hybrid technique. This design had traps expertly placed along streams, and traps in a grid formation at $9 \mathrm{~km}$ spacing, located $\geq 15 \mathrm{~km}$ from anadromous streams.

For each sampling configuration, we recorded a capture when a bear's GPS location occurred $\leq 500 \mathrm{~m}$ of a trap. All abundance estimates were then calculated with closed capture models in variation in capture probability associated with individuals or occasions (only one capture probability, $p$ ). Model $M_{t}$ assumed variation in capture probability between sampling sessions, but not among individuals within a session. Model $M_{h}$ (heterogeneity) permits different capture probabilities for individuals, which remains the same over all sampling occasions regardless of the capture history (Karanth et al., 2002). The fourth model, $M_{b}$, allows bears to demonstrate behavioral responses (e.g. trap happy or shyness), an effect which can exist in simulations (White, 2008). The remaining models allowed for combinations of the previous models $\left(M_{t h}, M_{t b}\right.$, $\left.M_{b h}, M_{t b h}\right)$

244 We used the program MARK to estimate abundance and the related metrics, based on the models receiving the most parsimonious fit. We used second-order Akaike's Information Criterion

$246\left(\mathrm{AIC}_{c}\right)$ for model selection and treated models with $\triangle \mathrm{AIC}_{c} \leq 2$ as competitive (Anderson \& 
247 Burnham, 2002; Burnham \& Anderson, 2002). We model averaged competitive models based on 248 model weights.

249 We evaluated abundance estimates for each grid and targeted sampling design against 7 criteria. 250 First, we calculated average bias (how close the population estimate was to the true abundance 251 value) as:

$252 \operatorname{Bias}(\hat{N})=\frac{1}{n} \sum_{i=1}^{n}\left(\hat{N}_{i}-N\right)$

253 with $\widehat{N} \hat{N}$ representing the abundance estimate, $N$ the true abundance, and $n$ the number of 254 simulations (30). We reported this as a relative score, by dividing bias by true abundance $(N=$ 255 42). Next, we examined precision, the degree to which an individual estimate is repeatable or 256 reproducible. We reported coefficient of variation (CV) as a proportional measure of error in the 257 abundance estimates

$258 \quad \mathrm{CV}(\hat{N})=100 * \frac{S D(\hat{N})}{\hat{N}}$

259 Accuracy is a combination of these metrics (Williams et al., 2002), calculated as:

$\operatorname{RMSE}(\hat{N})=\sqrt{\frac{1}{n} \sum_{i=1}^{n}\left(\hat{N}_{i}-N\right)}$

$261 R M S E(\hat{N})$ was reported relatively, by dividing by true abundance $(N=42)$. We also reported 262 encounter rates, capture probabilities, and recapture probabilities. Encounter rates described the 
263

264

265

266

267

268

269

270

271

272

273

274

275

276

277

278

279

280

281

282

number of GPS fixes considered captures, divided by the total number of GPS fixes (for each bear). Capture probabilities were the number of bears caught divided by the total number of known bears. Recapture probabilities were calculated as the number of bears caught more than once, divided by the total number of bears captured. We used 2-sample $t$-tests to compare the number of bears captured and recaptured between stationary and moved traps for each scenario (Zar, 1999). If Levene's test for equality of variances indicated unequal variances, we used $t$-tests where equal variances were not assumed (SPSS, 2010).

We also calculated the amount of effort (trap-nights) required to acquire population estimates as a surrogate for cost. This value was the number of traps multiplied by the number of days sampled.

Lastly, we used program TRENDS to determine the number of survey years required to detect a given population change or trend (Gerrodette, 1993). Parameters were $\alpha=0.05,1-\beta$ (power) $=$

$0.8, \mathrm{CV}(\widehat{N}) \propto \sqrt{N}$, with a linear change over time. This exercise assisted with interpreting the influence of CV ( $\widehat{N}$ ) on the effectiveness of each scenario for monitoring abundance changes.

\section{RESULTS}

\section{Sampling Periods}


283 brown bears had most location fixes $<500 \mathrm{~m}$ of anadromous streams. On average, there were 58.0

284 GPS fixes per bear (SD 20.1) during this sampling period.

\section{Availability for Capture}

286 For grid-based and targeted sampling to produce reliable population estimates, all individuals in 287 the population must have traps available to capture them. To accomplish this with grids, 288 practitioners recommend that cell area match the average home range size of the target species 289 home range sizes for the brown bears we sampled. The mean value was $149.7 \mathrm{~km}^{2}$ (SD 149.8

$\mathrm{km}^{2}$ ). When considering home range sizes of females with cubs, the mean home range size was $141.3 \mathrm{~km}^{2}$ (SD $145.8 \mathrm{~km}^{2}$ ). A 12 x $12 \mathrm{~km}$ cell approximates either area (Fig. 2).

Sixty-seven percent of the bears had home range sizes below this value. A cell size of $25 \mathrm{~km}^{2}$ would miss $<5 \%$ of bears yet the effort involved in employing such a grid is logistically untenable (30,050 trap-nights) and would be exorbitantly costly for a study site this large. We evaluated grids with edge lengths of 7,9 and $11 \mathrm{~km}$, and the following proportions of bears had 297 home range sizes below each of these areas, respectively: $26 \%, 49 \%$ and $63 \%$.

However, traps (especially when expertly placed) may occur within the animals' home range, even if it is smaller than the cell size employed. Therefore, for each grid scenario (expertly 300 placed traps) we determined if each bear had a trap within its home range. The average number 301 of bears without traps in their home range for stationary traps was 4.4 (SD 1.9; $49 \mathrm{~km}^{2}$ ), 9.5 (SD $\left.3023.2 ; 81 \mathrm{~km}^{2}\right)$, and $14.8\left(\mathrm{SD} 2.1 ; 121 \mathrm{~km}^{2}\right)$. Moving traps between capture sessions reduced these 
303 values, whereby the following numbers of bears never had a trap within its home range 1 (49

$\left.304 \mathrm{~km}^{2}\right), 1\left(81 \mathrm{~km}^{2}\right)$, and $3\left(121 \mathrm{~km}^{2}\right)$.

305 For targeted sampling, the sampling frame was the area within $500 \mathrm{~m}$ of an anadromous stream.

306 All bears were located within $500 \mathrm{~m}$ of anadromous streams during the sampling session, except

307 for 1997, when 2 bears were unavailable (although these bears were $\leq 500 \mathrm{~m}$ of streams after the 308 sampling session; Table 2).

309 Because one to three bears were always unavailable for capture, by definition, grid-based and 310 targeted sampling generated population indices, not estimates (hereafter termed indices). As 311 indicated, moving traps attenuates the problem of ensuring that all bears have equal opportunity 312 of encountering traps, but did not fix it.

\section{Evaluation of Sampling Configurations}

314 For each sampling configuration, we evaluated abundance indices, encounter rates, capture 315 probabilities, recapture probabilities, and the effort required to acquire them. For grids, the 316 configurations with traps in cell centers or randomly placed produced the lowest capture 317 probabilities, and generated abundance indices with high bias and error. Targeted sampling with 318 traps systematically placed also generated inaccurate abundance indices, and the hybrid 319 configuration provided results similar to targeted sampling alone. Therefore, we did not present 320 or consider these sampling designs further. 
321 We focused on configurations with traps expertly placed in each cell (Table 3). Within each

322 configuration, sampling with traps moved between capture sessions always provided more

323 accurate population indices than sampling with stationary traps, mainly because moving traps

324 halved bias. Moving traps always increased precision for targeted sampling, but inconsistently for 325 grids (Table 3).

326 Sampling with traps moved between capture sessions using $49 \mathrm{~km}^{2}$ cells and targeted sampling

327 generated the most accurate population indices (Table 3$)$. The $49 \mathrm{~km}^{2}$ grid had least bias (328 10.5\%) and low precision (CV 21.2\%), while targeted sampling had more bias (-17.3\%) and most 329 precision (CV 12.3\%). Their accuracy was nearly equivalent (RMSE $=21.7 \%$ and $20.0 \%$ 330 respectively; Table 3).

331 Grid-based sampling with moved traps in $81 \mathrm{~km}^{2}$ cells and with stationary traps in $49 \mathrm{~km}^{2}$ cells 332 also generated similar accuracy $(\mathrm{RMSE}=26.5 \%$ and $25.6 \%)$. The $81 \mathrm{~km}^{2}$ configuration had less

333 bias (-13.0), and more error (CV 26.6\%), while stationary traps in the $49 \mathrm{~km}^{2}$ grid had greater

334 bias (-21.5) and less error (CV 17.8\%). Sampling in the $121 \mathrm{~km}^{2}$ cells or with half the amount of 335 targeted traps (stationary) generated the most inaccurate indices, due to combinations of high bias 336 and imprecision (Table 3).

337 Usually, the techniques used to estimate or index abundance should be robust enough to identify 338 a specified level of change, be it the time necessary to quantify a given population trend, or the 339 time required to measure a set difference between individual surveys. For example, on the Kenai 
340 Peninsula, this brown bear population has a growth rate $(\lambda)$ of 1.04 (S. Farley, unpublished data).

341 At best, it would take $\geq 16$ years to detect this trend with grid-based sampling $\left(49 \mathrm{~km}^{2}\right.$ grids with 342 stationary traps). The targeted configuration required 12 years (moved traps; Table 4). A

343 doubling of population size is detectable in 19 or 28 years using a grid of $49 \mathrm{~km}^{2}$ with traps 344 stationary or moved, respectively. Targeted sampling required 10 years (moved traps). Were a 345 population to halve in size, the same grid scenarios would require 6 and 7 years to detect it, while 346 targeted sampling would take 4 years (Table 4$)$.

347 Encounter rates, capture probabilities, recapture probabilities and effort

348 Encounter rates within each grid and targeted configuration remained identical between traps 349 stationary or moved (moving traps reduced variability). Encounter rates for the targeted scenario 350 (moved traps) was 4 times greater than the best grid scenario ( $49 \mathrm{~km}^{2}$; Table 5$)$.

351 Within each configuration, moving traps always resulted in higher capture probabilities than 352 stationary traps. The increases were between 10 and 33\% (Table 6). Targeted sampling generated 353 the highest capture probabilities. With moved traps, capture probabilities were $11 \%$ higher than

354 sampling within the $49 \mathrm{~km}^{2} \operatorname{grid}(t=-5.1, d f=52.2, \mathrm{p}$-value $<0.001)$.

355 Within a given configuration, moving traps always reduced recapture probability. The result was

356 significant for every configuration except when sampling within $49 \mathrm{~km}^{2}$ grids (Table 7). The 357 recapture probabilities declined with increasing cell size $\left(49 \mathrm{~km}^{2}\right.$ and $81 \mathrm{~km}^{2}$ grids $)$, or with 
358 fewer targeted traps. For grids, recapture probabilities were greater for $121 \mathrm{~km}^{2}$ cells with

359 stationary traps, because the scenario caught fewer bears more often (Table 7). We found that

360 targeted sampling with moved traps had higher recapture probabilities than sampling in $49 \mathrm{~km}^{2}$

361 grids $(t=-13.2, d f=58, \mathrm{p}$-value $<0.001)$.

362 Lastly, effort (measured by trap-nights) was highest for grid sampling with 49 and $81 \mathrm{~km}^{2}$ cells, 363 as these scenarios expended 16,100 and 9,750 trap-nights each. Effort for the targeted

364 configuration was $57 \%$ less than the $49 \mathrm{~km}^{2}$ grids and $28 \%$ less than $81 \mathrm{~km}^{2}$ grids $(7,000$ trap365 nights; Table 1).

\section{DISCUSSION}

367 Establishing defensible and economical sampling methods to obtain species abundances will 368 inform conservation measures and management actions for many species inhabiting large, remote 369 or complicated landscapes. Therefore, we used a CMR framework and evaluated sampling 370 designs which varied by configuration, effort (trap amount) and complexity (stationary or 371 moved). The goal was to identify informative and affordable sampling designs that biologists 372 could use for estimating or indexing abundance.

373 For grid-based sampling, it is often recommended that cell size corresponds to the average area of 374 an animal's home range, or smaller, to reduce capture heterogeneity (Boulanger et al., 2004;

375 Boulanger et al., 2006; Sawaya et al., 2012). However, animal home ranges usually have much

376 variability, which can change within and across seasons based on resource pulses and their 377 distribution (McNab, 1963; Boulanger et al., 2006, Nielsen et al., 2010). Therefore, a value 
describing the average home range size may not be biologically meaningful, making it risky to

379 justify grid resolution on this metric. In our case, cell sizes of 49,81 and $121 \mathrm{~km}^{2}$ seemed

380 appropriate since female brown bears had home range sizes averaging $149.6 \mathrm{~km}^{2}$. Yet these cell

381 sizes were still too large for grid sampling to provide population estimates, since some bears were 382 not available for capture.

383 When grid configurations are used, justification for the cell size should not rely on the average 384 home range size of the target species. Instead, justification falls on making cell size as small as 385 project costs allow. However, to make studies affordable, the temptation is for fewer traps to be 386 employed, and therefore, increased cell size. Yet we found that as the grid cells became larger, 387 less numbers of traps caught fewer bears, which lowered encounter rates, capture and recapture 388 probabilities (Tables 5, $6 \&$ 7). This produces results with more bias and imprecision (Table 3 ). 389 Given this information, how does one know when cell sizes are too large?

390 Unless preliminary work provides information for understanding a species use of the landscape, 391 then the cell size chosen will be a speculation. As a result, the abundance estimate generated may 392 indicate an estimate or an index, or be completely uninformative.

393 Previously, many projects that estimated brown bear abundance operated in places spanning $394 \sim 2,000-8,000 \mathrm{~km}^{2}$ (e.g. Poole et al., 2001; Boulanger et al., 2002; Mowat et al., 2005;

395 Boulanger et al., 2006, Kendall et al., 2008). Our site spanned 16,000 $\mathrm{km}^{2}$. For areas of this 396 size, small grids grow prohibitively expensive to use. In our case, cell size should be $<49 \mathrm{~km}^{2}$, 397 requiring $>322$ traps and $>16,100$ trap-nights $\left(>0.02\right.$ traps $\left./ \mathrm{km}^{2}\right)$. Checking these traps in remote 398 locations usually requires the use of helicopters, which often exceed $\$ 700.00$ per flight hour. 
399

400

401

402

403

404

405

406

407

408

409

410

411

412

413

414

415

416

417

418

419

Project costs can easily approach $\$ 1,000,000.00$ in such large areas, when sampling in grids at or below this resolution. In any event, grid sampling places many traps in low density, to sample low densities of animals across an expansive area. It seems costly and inefficient.

For the targeted design, species biology informed the sampling frame, as anadromous streams attracted bears from the wider landscape. The technique was more efficient, by operating 140 traps in a $3,500 \mathrm{~km}^{2}$ area $\left(0.04\right.$ traps $\left./ \mathrm{km}^{2}\right)$. It sampled higher densities of animals in a smaller area with less traps, generating the highest capture and recapture probabilities (Tables $6 \& 7$ ). Its accuracy was equivalent to the grid index $\left(49 \mathrm{~km}^{2}\right.$; Table 3$)$.

For brown bears in Alaska, the targeted configuration is easier and cheaper to operate in the field for at least three reasons. First, it required half the effort of the $49 \mathrm{~km}^{2}$ grids. Second, since traps occur along streams, they are more accessible by walking or rafting. Third, the lure (fish) is provided naturally, reducing time, expense and costs for trap set-up, and concerns that the target species may lose interest in the trap over time (Boulanger et al. 2004a; Boulanger et al. 2008b).

The conventional assumption is that moving traps raises capture probabilities, by increasing the proportion of bears captured, and therefore reducing bias (Boulanger et al.,2002; Boulanger et al., 2004a; Boulanger et al., 2006). Our simulation confirmed this assumption for grid and targeted sampling, as moving traps always increased capture probabilities. Moving traps between capture sessions raised capture probabilities, because moving traps to new areas increased their availability to more bears that would otherwise not have the opportunity to encounter them. However, moving traps also caused a decline in recapture probabilities. This makes sense, as moving traps takes them from a location where they already sampled bears, and places them 
420

421 the trap is more likely to be moved to a spot where they do not occur. The $49 \mathrm{~km}^{2}$ grid had most 422

423

someplace new. Then, it becomes more difficult to recapture those same bears already caught, as traps, which may explain why the effects of relocating traps was not as marked.

For indexing species abundances, the most accurate results occurred with traps moved between capture sessions, and traps placed by expert opinion. Moving traps reduced capture heterogeneity, by increasing the number of animals in the sampling frame with a nonzero probability of encountering a trap (Williams et al., 2002; Lukacs 2009). Unfortunately, moving traps did not ensure trap availability to all bears, and therefore did not completely alleviate the sampling bias caused by using too large a cell, or sampling at anadromous streams. All individuals in the population must visit the sampling area to generate valid estimates of abundance. Hence, the final abundances generated from both sampling designs represented population indices. Providing population estimates would require smaller grid cells, or more traps in the targeted design.

\section{Sampling synopsis}

The most accurate configurations, targeted and grid-based sampling with $49 \mathrm{~km}^{2}$ cells, had tradeoffs in bias, precision and effort (costs). Targeted sampling was more biased and precise while the $49 \mathrm{~km}^{2}$ grid was less biased and less precise. Because abundances gained from grid sampling tend to be imprecise, some projects incorporate ancillary information (i.e. covariates) to increase precision, or data from captures gained elsewhere (Boulanger et al., 2008b; Kendall et al., 2009; Sawaya et al., 2012). Many applications to index abundance for bears and other species will not have such ancillary data available, and therefore we did not include covariates in our analyses. 
441 Often, management applications center on evaluating trends in abundances over time. Because

442 this exercise requires high precision, most wildlife surveys aim for a $\mathrm{CV} \leq 20 \%$ (Boulanger et

443 al., 2002; Williams et al., 2002). Otherwise, it takes unacceptably long to measure population

444 changes and trends in time for managers to act. The most accurate targeted scenario met the

445 criteria, by generating a CV of $12 \%$, while the most accurate $49 \mathrm{~km}^{2}$ grid did not.

446 When using the program MARK, the most competitive models for grids (moved traps) typically 447 contained $M_{o}$ models $\left(80 \% 49 \mathrm{~km}^{2}, 86 \% 81 \mathrm{~km}^{2}\right)$, and rarely $M_{h}$ based models. This outcome is 448 indicative of grid sampling reducing heterogeneity between capture sessions. However, $M_{o}$ based 449 models are sensitive to violations in the underlying model assumption of homogenous capture 450 probabilities (Otis et al., 1978). For the targeted approaches, we anticipated variation in capture 451 probability among individuals, and found that all targeted configurations (moved traps) used $M_{h}$ 452 based models. The $M_{h}$ models are robust to violations in underlying model assumptions, 453 providing greater confidence in those abundance estimates (Burnham \& Overton, 1978; Otis et 454 al., 1978; Karanth et al., 2002).

455 Given this synopsis, targeted sampling provides results with accuracy comparable to grid 456 sampling, only more affordably. Hence, targeted sampling opens opportunities for indexing 457 abundances of animal populations for many conservation and management projects, provided that 458 the species are attracted to resource concentrations. Often, these projects are cost limited, large in 459 geographical size, focus on rare and sparsely distributed species, and cover locations with 460 challenging access. The abundance indices gained would contribute toward understanding 461 population changes between periods and measuring the trajectory of populations over time, for 462 many species whose current information is deficient. 


\section{Encounter distance and use of lure}

464 The effective distance that a bear would be attracted to a scent or visual lure is unknown. The

465 distance depends on the type of lure used, amount of elapsed time since lure deployment (more

466 time dilutes lure effectiveness), topography, weather (e.g. aridity, precipitation), wind speed and

467 direction, bear gender, experience and behavior (i.e. waning interest in lure; Boulanger et al.,

468 2004a; Boulanger et al., 2008b; Sawaya et al., 2012). Potentially, future studies aimed at

469 quantifying this distance could leverage off projects that estimate population sizes of lions

470 (Panthera leo) and hyenas (Crocuta crocuta) using call playbacks as lure (Mills et al., 2001;

471 Kiffner et al., 2008).

472 Our simulation considered distances between a bears GPS location and hypothetical trap $<500 \mathrm{~m}$ 473 as encounters. The actual distance used is essentially irrelevant for the simulation. What matters

474 is bear density in a given area. Areas with high bear density will get more captures than a place

475 with low density, regardless of the distance between bear and trap. In our example, targeted

476 sampling occurred in a confined area, defined as places within $500 \mathrm{~m}$ of anadaramous streams.

477 Since all bears visit this relatively small area - about $88 \%$ smaller than the grid area - then traps

478 placed here catch more bears more often. The wider landscape has lower density of bears, so

479 traps placed there catch fewer bears less often. Preliminary work with a 100 m encounter

480 distance generated similar outcomes to those presented here, only with less encounters and

481 captures (G. Harris, unpublished data). Seemingly, by considering larger encounter distances, it

482 would generate more encounters and captures. 
483

484

485

486

487

488

489

490

491

492

493

494

495

496

497

498

499

500

501

502

503

504

Because our effort is a simulation, it did not account for baiting traps, a common practice to attract bears when field sampling (e.g. Woods et al., 1999; Boulanger et al. 2002; Sawaya et al. 2012). Were a field study to occur, with traps baited, then we would expect encounter probabilities to increase, for grid and targeted sampling alike. Both sampling designs can have lure associated with them (Sawaya et al., 2012). Therefore, in the simulation, since data are handled identically, there is no more attraction for a bear to visit a targeted snare any more so than a grid snare. Additionally, the behavioral responses measured in the modeling can reflect survey configuration (White, 2008).

As above, what differs is bear density in an area. The targeted sampling frame matched species biology by relying on animals' attraction to resource concentrations (Karanth et al., 2004). This outcome enabled targeted sampling to provide accurate abundance indices. The targeted approach is not new, and has been used elsewhere to provide abundance data with informative results, be it rub trees to collect bear hair (e.g. Mowat et al., 2005; Kendall et al., 2008; Kendall et al., 2009; Sawaya et al., 2012) or to gain photographs of tigers along trails (Karanth \& Nichols, 1998).

\section{Spatial capture-recapture models}

We relied on closed capture models in the program MARK (White \& Burnham, 1999) to quantify abundances, instead of other approaches such as spatially explicit capture-recapture models (SECR; Efford et al., 2009; Efford, 2011; Royle et al., 2011). While the SECR approach can apply to grid sampling, and we applaud the innovation, there are five reasons why we employed MARK. First, MARK is a proven method and appropriate for estimating animal abundances. Second, this project is a simulation, with all bears completely within the study frame, and the population closed (based on the GPS location data). This eliminated any ambiguity over the 
505 effective sampling area, which the SECR models rigorously address for the purposes of density 506 estimation. Third, when grid cells exceed home range size - as encountered herein - then not all 507 individuals are available for capture. SECR models do not solve this bias. Fourth, the SECR 508 models rely on information describing where and when a given animal is trapped (session 509 number) to identify each individual animals "activity center". The probability of detection for 510 each trap is modeled as a function of the distance from the activity center to traps in the array. If 511 the method relies on animal movements to estimate home range centers (Royle et al., 2009), then 512 SECR requires multiple captures. Yet, over one-third of these bears had only one capture (each, 513 for $49 \mathrm{~km}^{2}$ and $81 \mathrm{~km}^{2}$ grid cells with moved traps). This renders the SECR technique less 514 effective. Fifth, some SECR models assume that activity centers are uniform and symmetric 515 (Efford et al., 2009; Efford, 2011; Royle et al., 2011). Unfortunately, this assumption is untenable 516 for brown bears inhabiting the Kenai Peninsula. Home range sizes varied widely in area (Fig. 2), 517 and spatially, as bears often moved linearly within mountain valleys and through passes, thereby 518 defying the notion of a symmetrical home range (G. Harris and S. Farley, unpublished data).

519 Unfortunately, SECR models are not yet designed for data gained by a targeted approach (J. A. 520 Royle, pers. comm. 2013). If activity centers were built for bears trapped at streams, it would 521 imply that bears only occurred there. This would severely bias the true distribution of bear's 522 activity centers across the landscape. In reality, bear movements follow a general pattern 523 whereby they periodically visit streams as they wander throughout the wider landscape (G. Harris $524 \&$ S. Farley, unpublished data). Therefore, by using MARK to compute abundance indexes, it 525 ensured that each of the scenarios contained similar sampling and quantitative assumptions.

\section{Density estimation}


527 An important part of abundance estimation is defining the sampling area, and determining if that

528 area is open or closed to species movement. For targeted sampling, defining the study area

529 requires knowing the "attraction distance" of the species to the resource concentrations (where

530 sampling occurs). We do not know the attraction distance of brown bears to anadromous streams.

531 However, in our study, all bears spanning the peninsula visited anadromous streams. Because the

532 attraction distance was not exceeded for these bears, a targeted sampling design actually

533 conducted on the Kenai Peninsula could estimate density. Obviously, this is not the case for

534 many other species and locations. For them, additional work will probably be required to

535 determine the attraction distance, which would in turn define the sampling frame. Fortunately,

536 there is precedence for such efforts, as biologists on the African continent estimate abundance of

537 lions and hyenas based on their attraction to vocalization lures. Biologists quantified the

538 attraction distance of these carnivores to the lure, to estimate species density (Ogutu \& Dublin, 539 1998).

540 CONCLUSIONS

541 When sampling cryptic animals inhabiting thickly vegetated and expansive areas, with DNA,

542 camera traps or other CMR methodology, it can challenge abilities to produce accurate and

543 affordable abundance indices. Yet targeted sampling met these criteria, by sampling where

544 individuals gathered in smaller areas, at biologically important places and times. It generated

545 encounter rates four times higher than grid sampling, capture probabilities $11 \%$ higher, and $60 \%$

546 higher recapture probabilities. This reduced capture heterogeneity (Williams et al., 2002; Lukacs,

547 2009). By generating a CV of $12 \%$, targeted sampling was precise. Better precision enables

548 measuring changes in abundances quicker, with trends more likely to reflect true changes in the 
549 population and not sampling or biological artifacts. Lastly, targeted sampling was more

550 economical, as it used half the effort of the grid.

551 Since our simulation had a known number of bears, it enabled us to evaluate the veracity of the 552 grid and targeted designs. Hence, our simulation provided insight into sampling approaches and 553 assumptions for grid and targeted sampling that would be difficult to provide with field studies. 554 However, conducting field studies to test and verify our findings, or refine methodologies, forms 555 a logical next step. Fortunately, for targeted sampling, some field studies already provide insight. 556 For instance, Saway et al. (2012) found that collecting hair from bear rubs generated higher 557 detection rates and capture probabilities than traps in grids, for all classes of bears. Kendall et al. 558 (2009) also relied on collecting hair on bear rubs and from physical captures to improve capture 559 probabilities, as samples gained from grid traps alone provided inaccurate results.

560 Grids blanket entire study areas under the guise of ensuring equal probability of capture. This 561 approach should work, provided the cells are small enough to encapsulate home ranges of all 562 individuals. This requires home range data, which can be expensive and laborious to procure. If 563 the average home range size is used, or were cell size based on home range data gained 564 elsewhere, or home range sizes changed between surveys, then cell sizes may be too large. Then, 565 users of grid sampling may assume that their techniques meet the sampling assumptions required 566 to estimate population abundance, when in actuality, not all individuals are available for capture. 567 Worryingly, many studies have not confirmed that the cell sizes they employ are appropriate (e.g. 568 Woods et al., 1999; Boulanger et al., 2004; Mowat et al., 2005; Boulanger et al., 2006;

569 Boulanger et al., 2008; Kendall et al., 2008; Sawaya et al., 2012). Therefore, their results may 570 represent estimates or indices, and if the latter, how the index relates to the estimate is unknown. 
571 Criticism of the targeted approach centers on subjective or convenience sampling, largely

572 regarded as poor practice. As with grids, to ensure that subjective sampling does not occur,

573 studies should demonstrate that individuals have a nonzero probability of capture (to produce

574 estimates). Unfortunately, other studies using targeted sampling have not justified if all

575 individuals in the sampling frame have a nonzero probability of capture, so whether these studies

576 meet this assumption also remains unknown (Karanth et al., 1998; Kendall et al., 2009; Sawaya

577 et al., 2012).

578 We found that grid and targeted sampling of brown bears on the Kenai Peninsula had a few 579 individuals with zero probability of capture, and therefore did not meet this assumption. The 580 extent that serious problems in wildlife management or conservation stem from studies sampling 581 with grids or targeted designs and presenting estimates that could represent indices remains 582 uncertain. However, in keeping with our results, the biases are likely to be negative, thereby 583 erring conservatively. Although, the trends for grids would likely be less informative than the 584 trends reported from targeted designs, because the grid designs were more imprecise, which 585 could mask population changes when they occur.

586 The targeted approach relied on identifying biologically important resource concentrations, and 587 sampling at those sites. For bears, salmon runs may change in timing between periods, so bears 588 could visit them outside the sampling period. Or, some resource concentrations may be unknown, 589 and therefore not sampled. If so, the cost of inadequately covering all resource concentrations is 590 larger bias. However, population indices from the targeted design maintained precision, 591 rendering them useful for evaluating trend (provided traps were moved between sessions).

592 Therefore, the outcome of heterogeneity in animal captures for trend analyses manifests in grid 
593

594

595

596

597

598

599

600

601

602

603

604

605

606

607

608

609

610

611

612 Globally, many species inhabit expansive and inaccessible areas, and have sparse distributions

613 within them. Because these species are difficult to sample, data describing their abundances are

614 often deficient. Many of these animals are of high conservation concern. Biologists require

Biologists must weigh the theoretical robustness of sampling and modeling procedures with the logistical constraints of a given sampling design. Clearly, both grid and targeted sampling have benefits and flaws. Before employing these designs, practitioners should evaluate their sampling assumptions, the methodological drawbacks, and the utility of the results generated. The grid and targeted designs are not appropriate for all species in every situation. Neither approach is a panacea.

Targeted sampling could assist with indexing abundance of other species that concentrate at biological resources - be it trails, water holes, mineral licks, or animal latrines (Karanth et al., 2004). For example, travel routes and trail intersections draw tigers (Karanth \& Nichols, 1998).

The thick lowland forests of the Southwestern Amazon contain sparsely distributed macaws. Macaws gather by the hundreds to take clay from exposed riverbanks (Diamond, 1999). Similarly, burned patches in lowland Nepal attract axis deer (Axis axis) from forests (Moe \& Wege, 1997), while alpine ibex (Capra ibex) and bighorn sheep (Ovis canadensis) vacate rugged terrain to frequent natural and anthropogenic sources of salt and minerals (Schmidt et al., 1978; Watts \& Schemnitz, 1985; Bassano et al., 2003). Walruses (Odobenus rosmarus) aggregate at terrestrial haul-out sites (Lydersen et al., 2008) and elephants congregate at water sources (Harris et al., 2008). 
615 methods to sample these animals effectively and economically, for indexing abundance and

616 reporting trends, to subsequently conserve and manage their populations. In extensive areas

617 where animals concentrate in confined locations, targeted sampling could provide such an

618 approach.

\section{ACKNOWLEDGEMENTS}

620 We thank the Alaska Department of Fish and Game for continuing to support telemetry of brown 621 bears. Pilots J. DeCreft, R. Ernst, and M. Litzen ensured safe captures and data collection. M.

622 Conroy, T. Debruyn, J. Morton and J. Sanderson were generous with time, knowledge and ideas.

623 A. Jacobson, D.H. Johnson and other anonymous reviewers provided helpful comments to 624 strengthen this manuscript. The findings and conclusions in this article are those of the author(s) 625 and do not necessarily represent the views of the U.S. Fish and Wildlife Service. The use of trade, 626 firm, or product names is for descriptive purposes only and does not imply endorsement by the 627 U.S. Government.

\section{REFERENCES}

629 Anderson DR, Burnham KP. 2002. Avoiding pitfalls when using information-theoretic methods. 630 The Journal of Wildlife Management 66:912-918.

631 Bassano B, von Hardenberg A, Pelletier F, Gobbi G. 2003. A method to weigh free-ranging 632 ungulates without handling. Wildlife Society Bulletin 31:1205-1209. 
633

634

635

636

637

638

639

640

641

642

643

644

645

646

647

648

649

650

651

652

653

654

Beier LR, Lewis SB, Flynn RW, Pendleton G, Schumacher TV. 2005. A single-catch snare to collect brown bear hair for genetic mark-recapture studies. Wildlife Society Bulletin 33: 766773.

Boulanger J, White GC, McLellan BN, Woods J, Proctor M, Himmer S. 2002. A meta-analysis of grizzly bear DNA mark-recapture projects in British Columbia, Canada: Invited paper. Ursus 13: $137-152$.

Boulanger J, Himmer S, Swan C. 2004a. Monitoring of grizzly bear population trends and demography using DNA mark-recapture methods in the Owikeno Lake area of British Columbia. Canadian Journal of Zoology 82: 1267-1277.

Boulanger J, Stenhouse G, Munro R. 2004b. Sources of heterogeneity bias when DNA markrecapture sampling methods are applied to grizzly bear (Ursus arctos) populations. Journal of Mammalogy 85: 618-624.

Boulanger J, Proctor M, Himmer S, Stenhouse G, Paetkau D, Cranston J. 2006. An empirical test of DNA mark-recapture sampling strategies for grizzly bears. Ursus 17: 149-158.

Boulanger J, Kendall KC, Stetz JB, Roon DA, Waits LP, Paetkau D. 2008a. Multiple data sources improve DNA-based mark-recapture population estimates of grizzly bears. Ecological Applications 18: 577-589.

Boulanger J, White GC, Proctor M, Stenhouse G, Machutchon G, Himmer S. 2008b. Use of Occupancy Models to Estimate the Influence of Previous Live Captures on DNA-Based Detection Probabilities of Grizzly Bears. The Journal of Wildlife Management 72: 589-595.

Burnham KP, Overton WS.1978. Estimation of the size of a closed population when capture probabilities vary among animals. Biometrika 65: 625-633. 
655 Burnham KP, Anderson DR. 2002. Model selection and mulitmodel inference: a practical 656 information-theoretic approach. New York: Springer-Verlag.

657 Diamond JM. 1999. Evolutionary biology: Dirty eating for healthy living. Nature 400: 120-121.

658 Efford MG, Dawson DK, Borchers DL. 2009. Population density estimated from location of 659 individuals on a passive detector array. Ecology 90:2676-2682.

660 Efford MG. 2011. Estimation of population density by spatially explicit capture-recapture 661 analysis of data from area searches. Ecology 92: 2202-2207.

662 Fuller TK. 1995. An international review of large carnivore conservation status. In: Bissonette 663 JA, Krausman PR, eds. Integrating people and wildlife for a sustainable future. Bethesda: The 664 Wildlife Society. 410-412.

665 Gerrodette T. 1993. Trends: software for a power analysis of linear regression. Wildlife Society $666 \quad$ Bulletin 21:515-516.

667 Harris GM, Russell GJ, van Aarde RJ, Pimm SL. 2008. Rules of habitat use by elephants 668 Loxodonta africana in southern Africa: insights for regional management. Oryx 42: 66-75.

669 Harris RB, Winnie Jr J, Amish SJ, Beja-Pereira A, Godinho R, Costa V, Luikart G. 2010. Argali 670 abundance in the Afgan pamir using capture-recapture modeling from fecal DNA. Journal of $671 \quad$ Wildlife Management 74: 668-677.

672 Hilderbrand GV, Schwartz CC, Robbins CT, Jacoby ME, Hanley TA, Arthur SM, Servheen C.

673 1999. The importance of meat, particularly salmon, to body size, population productivity, and 674 conservation of North American brown bears. Canadian Journal of Zoology 77: 132-138. 
675 Hooge PN, Eichenlaub B. 2000. Animal movement extension to Arcview. ver. 2.0. Anchorage:

676 Alaska Science Center - Biological Science Office, U.S. Geological Survey.

677 Karanth KU, Nichols JD. 1998. Estimation of tiger densities in India using photographic captures 678 and recaptures. Ecology 79: 2852-2862.

679 Karanth KU, NS Kumar, Nichols JD. 2002. Field Surveys: Estimating absolute densities of tigers 680 using capture-recapture sampling. In: Karanth KU, Nichols JD, eds. Monitoring tigers and 681 their prey: A manual for researchers, managers and conservationists in tropical Asia. 682 Bangalore: Centre for Wildlife Studies.139-152.

683 Karanth KU, Nichols JD, Kumar NS. 2004. Photographic sampling of elusive mammals in 684 tropical forests. In: Thompson WT, ed. Sampling Rare or Elusive Species: Concepts, designs, 685 and techniques for estimating population parameters. Washington D.C.: Island Press. 229686247.

687 Kendall, KC, Stetz JB, Roon DA, Waits LP, Boulanger JB, Paetkau, D. 2008. Grizzly bear 688 density in Glacier National Park, Montana. The Journal of Wildlife Management 72: 1693$689 \quad 1705$.

690 Kendall KC, Stetz JB, Boulanger J, Macleod AC, Paetkau D, White GC. 2009. Demography and 691 genetic structure of a recovering grizzly bear population. The Journal of Wildlife 692 Management 73: 3-16.

693 Kindberg J, Swenson JE, Ericsson G, Bellemain E, Miquel C, Taberlet P. 2011. Estimating 694 population size and trends of the Swedish brown bear Ursus arctos population. Wildlife 695 Biology 17: 114-123. 
696 Kiffner C, Waltert M, Meyer B, Mühlenberg M. 2008. Response of lions (Panthera leo

697 LINNAEUS 1758) and spotted hyaenas (Crocuta crocuta ERXLEBEN 1777) to sound

698 playbacks. African Journal of Ecology 46: 223-226.

699 Lukacs P. 2009. Closed population capture-recapture models. In Cooch E, White G. eds. Program

700 MARK: a gentle introduction. Available: http://www.phidot.org/software/mark/docs/book/.

$701 \quad$ July 2009. pp. 14-1-14-26.

702

Lydersen C, Aars J, Kovacs KM. 2008. Estimating the number of walruses in Svalbard from

703 aerial surveys and behavioural data from satellite telemetry. Arctic 61: 119-128.

704

MacArthur RH. 1972. Geographical Ecology: Patterns in the distribution of species. Princeton:

705 Princeton University Press.

706

McNab BK. 1963. Bioenergetics and the determination of home range size. The American

707 Naturalist 97:133-140.

708

Miller SD, White GC, Sellers RA, Reynolds HV, Schoen JW, Titus K, Barnes VG Jr, Smith RB,

709 Nelson RR, Ballard WB, Schwartz CC. 1997. Brown and black bear density estimation in $710 \quad$ Alaska using radiotelemetry and replicated mark-resight techniques. Wildlife Monographs $711 \quad 133$.

712 Mills MGL, Juritz JM, Zucchini W. 2001. Estimating the size of spotted hyaena (Crocuta 713 crocuta) populations through playback recordings allowing for non-response. Animal 714 Conservation, 4(4), 335-343.

715 Moe SR, Wegge P. 1997. The effects of cutting and burning on grass quality and axis deer .Axis 716 axis. use of grassland in lowland Nepal. Journal of Tropical Ecology 13: 279-292. 
717 Mowat G, Heard DC, Seip DR, Poole KG, Stenhouse G, Paetkau DW. 2005. Grizzly Ursus arctos

718 and black bear U. americanus densities in the interior mountains of North America. Wildlife

$719 \quad$ Biology 11:31-48

720 Nichols JD, KU Karanth. 2002. Statistical concepts: Estimating absolute densities of tigers using

721 capture-recapture sampling. In Karanth KU, Nichols JD, eds. Monitoring tigers and their

722 prey: A manual for researchers, managers and conservationists in tropical Asia. Bangalore:

$723 \quad$ Centre for Wildlife Studies. 121-137.

724 Nielsen SE, McDermid G, Stenhouse GB, Boyce MS. 2010. Dynamic wildlife habitat models:

725 seasonal foods and mortality risk predict occupancy-abundance and habitat selection in

726 grizzly bears. Biological Conservation 143: 1623-1634.

727 Ogutu JO, Dublin HT. 1998. The response of lions and spotted hyaenas to sound playbacks as a

728 technique for estimating population size. African Journal of Ecology 36: 83-95. doi:

$729 \quad$ 10.1046/j.1365-2028.1998.113-89113.x

730

Otis DL, Burnham KP, White GC, Anderson DR. 1978. Statistical inference from capture data on closed animal populations. Wildlife monographs 62: 3-135.

732 Poole KG, Mowat G, Fear DA. 2001. DNA-based population estimate for grizzly bears Ursus

733 arctos in northeastern British Columbia, Canada. Wildlife Biology 7:105-115.

734 Powell RA. 2000. Animal home ranges and territories and home range estimators. In Boitaini L,

735 Fuller TK, eds. Research techniques in animal ecology: controversies and consequences. New

736 York: Columbia University Press. 65-110. 
737 Royle JA, Magoun AJ, Gardner B, Valkenburg P, Lowell RE. 2011. Density estimation in a

738 wolverine population using spatial capture-recapture models. The Journal of Wildlife

$739 \quad$ Management 75: 604-611.

740 Royle JA, Karanth KU, Gopalaswamy AM, Kumar NS. 2009. Bayesian inference in camera

741 trapping studies for a class of spatial capture-recapture models. Ecology 90: 3233-3244.

742 Sawaya MA, Stetz JB, Clevenger AP, Gibeau ML, Kalinowski ST. 2012.. Estimating grizzly and 743 black bear population abundance and trend in Banff National Park using noninvasive genetic $744 \quad$ sampling. PloS one 7 e34777.

745 Schmidt RL, Rutherford WH, Bodenham FM. 1978. Colorado bighorn sheep-trapping $746 \quad$ techniques. Wildlife Society Bulletin 6: 159-163.

747 Shackleton DM (Ed.). 1997. Wild sheep and goats and their relatives: status survey and 748 conservation action plan for Caprinae (Vol. 33). IUCN.

749 SPSS.2010. IBM ${ }^{\circledR}$ SPSS ${ }^{\circledR}$ statistics 19.0. SPSS Inc., Armonk, New York, USA.

750 Watts TJ, Schemnitz SD. 1985. Mineral lick use and movement in a remnant desert bighorn sheep 751 population. The Journal of wildlife management 49: 994-996.

752 Weber W, Rabinowitz A. 1996. A global perspective on large carnivore conservation.

753 Conservation Biology 10: 1046-1054.

754 White GC. 2008. Closed population estimation models and their extensions in Program MARK.

755 Environmental and Ecological Statistics 15: 89-99.

756 White GC, Burnham KP. 1999. Program MARK: Survival estimation from populations of 757 marked animals. Bird Study 46 Supplement: 120-138. 
758 Williams BK, Nichols JD, Conroy M. 2002. Analysis and management of animal populations.

759 San Diego: Academic Press.

760 Woods JG, Paetkau D, Lewis D, McLellan BN, Proctor M, Strobeck C. 1999. Genetic tagging of

761 free-ranging black and brown bears. Wildlife Society Bulletin 27: 616-627.

762 Zar JH.1999. Biostatistical analysis. Second edition. Upper Saddle River: Prentice Hall. 


\section{Table $\mathbf{1}_{\text {(on next page) }}$}

\section{Sampling configurations.}

Characteristics of the sampling configurations used to simulate capture-mark-recapture of brown bears on the Kenai Peninsula, south-central Alaska, USA. Attributes included the timing of the simulation (period), position of traps (placement), whether traps were stationary or moved between capture sessions, cell area $\left(\mathrm{km}^{2}\right)$ or trap spacing apart $(\mathrm{km})$, the number of traps in each of 5 capture sessions, and effort (trap-nights). 
Table 1

\begin{tabular}{|c|c|c|c|c|c|c|c|}
\hline $\begin{array}{l}\text { Sampling } \\
\text { Configuration }\end{array}$ & Perigd & Placement & $\begin{array}{l}\text { Stationary (S) } \\
\text { or Moved (M) }\end{array}$ & $\begin{array}{l}\text { Cell Area } \\
\text { or Spacing }\end{array}$ & $\begin{array}{l}\text { No. Traps per } \\
\text { Capture Session }\end{array}$ & $\begin{array}{l}\text { Total Effort } \\
\text { (Trap-Nights) }\end{array}$ & \\
\hline Grid & $6 / 1-8 / 20$ & Cell Center & $\mathrm{S}$ & $49,81,121$ & $322,195,135$ & $16,100,9,750,6,750$ & \\
\hline Grid & $6 / 1-\frac{\vec{z}}{\tau} / 20$ & Random & $\mathrm{S}$ & $49,81,121$ & $322,195,135$ & $16,100,9,750,6,750$ & \\
\hline Grid $^{\mathrm{a}}$ & $6 / 1-\frac{7}{7} / 20$ & Expert opinion & $\mathrm{S}$ & $49,81,121$ & $322,195,135$ & $16,100,9,750,6,750$ & \\
\hline Grid $^{\mathrm{a}}$ & $6 / 1-7 / 20$ & Expert opinion & M & $49,81,121$ & $322,195,135$ & $16,100,9,750,6,750$ & \\
\hline Targeted & $7 / 10 \operatorname{de}_{0} 8 / 28$ & Systematic & $\mathrm{S}$ & 17,19 & 324,312 & $16,200,15,600$ & \\
\hline Targeted $^{\mathrm{a}}$ & $\begin{array}{c}7 / 10 \geq 8 / 28 \\
\simeq \\
7,000,3,500\end{array}$ & $\begin{array}{c}\text { Expert opinion } \\
\text { Targeted }^{\mathrm{a}}\end{array}$ & $\begin{array}{l}\mathrm{S} \\
7 / 10-8 / 28\end{array}$ & $\begin{array}{l}\text { N/A } \\
\text { Expert opin }\end{array}$ & $\begin{array}{l}140,70 \\
\mathrm{nM}\end{array}$ & $\begin{array}{l}7,000,3,500 \\
\text { N/A }\end{array}$ & 140,70 \\
\hline
\end{tabular}




\section{Table 2 (on next page)}

\section{Availability for capture.}

The total number of bears on the Kenai Peninsula during the sampling period for the targeted scenario, along with the number of bears present within the sampling frame $(<500 \mathrm{~m}$ of an anadromous stream) during that period, for each year of sampling. 
Table 2

\begin{tabular}{ccc}
\hline Year & $\begin{array}{r}\text { Total No. Bears } \\
\text { In Sampling Period }\end{array}$ & $\begin{array}{c}\text { No. Bears Within } \\
\text { Sampling Frame }\end{array}$ \\
1996 & 2.0 & 2.0 \\
1997 & 14.0 & 12.0 \\
1998 & 4.0 & 4.0 \\
1999 & 8.0 & 8.0 \\
2000 & 6.0 & 6.0 \\
2003 & 5.0 & 5.0 \\
2004 & 3.0 & 3.0 \\
\hline
\end{tabular}




\section{Table 3 (on next page)}

\section{Comparison of sampling configurations.}

Results describing the bias, precision and accuracy of abundance estimates generated from the grid and targeted sampling configurations, with trap placement stationary or moved between capture sessions ( $N=42$ for each configuration). 
Table 3

\begin{tabular}{|c|c|c|c|c|c|c|c|}
\hline \multirow[b]{2}{*}{ Configuration } & \multirow[b]{2}{*}{ Placement } & \multicolumn{2}{|r|}{$\widehat{N}$} & \multicolumn{2}{|c|}{$\widehat{N}$} & \multirow[b]{2}{*}{$\% \operatorname{Bias}^{\mathrm{d}}$} & \multirow{2}{*}{$\% \mathrm{RMSE}^{\mathrm{e}} \mathrm{CV}$} \\
\hline & & $n^{\mathrm{a}}$ & $\mathrm{b}$ & SD & $\mathrm{c}$ & & \\
\hline \multirow[t]{2}{*}{ Grid 7km } & Stationary & 30 & 32.98 & 5.88 & -21.48 & 25.63 & 17.82 \\
\hline & Moved & 30 & 37.59 & 7.98 & -10.51 & 21.70 & 21.22 \\
\hline \multirow[t]{2}{*}{ Grid 9km } & Stationary & 30 & 29.96 & 10.57 & -28.67 & 38.16 & 35.30 \\
\hline & Motred & 30 & 36.56 & 9.72 & -12.95 & 26.51 & 26.58 \\
\hline \multirow[t]{2}{*}{ Grid $11 \mathrm{~km}$} & Stationary & 30 & 19.49 & 9.76 & -53.60 & 58.42 & 50.10 \\
\hline & Moved & 30 & 32.21 & 17.45 & -23.31 & 47.63 & 54.16 \\
\hline \multirow[t]{2}{*}{ Targeted } & St atsonary & 30 & 28.23 & 4.22 & -32.77 & 34.28 & 14.94 \\
\hline & Nemed & 30 & 34.75 & 4.26 & -17.27 & 20.02 & 12.26 \\
\hline \multirow[t]{2}{*}{ Targeted(1/2) } & Stationary & 30 & 20.36 & 5.00 & -51.51 & 52.87 & 24.56 \\
\hline & Moved & 30 & 27.42 & 4.32 & -34.71 & 36.20 & 15.75 \\
\hline \multicolumn{8}{|c|}{$\begin{array}{l}\text { a Sample size } \\
\text { b Mean estimated abundance }\end{array}$} \\
\hline \multicolumn{8}{|c|}{$\begin{array}{l}\text { c Standard deviation of mean estimated abundance. } \\
\text { d Percent relative bias }\end{array}$} \\
\hline
\end{tabular}




\section{Table 4 (on next page)}

Time required to measure population change.

Time (years) required to measure a lambda of 1.04 , and a doubling or halving of overall population size, from 5 different sampling configurations with traps stationary (S) or moved (M) between capture sessions. Calculations relied on CVs reported in Table 3. 
Table 4

\begin{tabular}{llll}
\hline Sampling Configuration & $\mathbf{T}_{\boldsymbol{\lambda}}{ }^{\mathbf{a}}$ & $\mathbf{T}_{\mathbf{d}} \mathbf{b}^{\mathbf{b}}$ & $\mathbf{T}_{\mathbf{h}}{ }^{\mathbf{c}}$ \\
Grid 7km (S) & 16 & 19 & 6 \\
Grid 7km (M) & 19 & 28 & 7 \\
Grid 9km (S) & 34 & 61 & 17 \\
Grid 9km (M) & 23 & 43 & 11 \\
Grid 11km (S) & 48 & 82 & 36 \\
Grid 11km (M) & 54 & 106 & 41 \\
Targeted (S) & 14 & 13 & 4 \\
Targeted (M) & 12 & 10 & 4 \\
Targeted(1/2) (S) & 21 & 36 & 9 \\
Targeted(1/2) (M) & 15 & 16 & 5 \\
& & & \\
\hline
\end{tabular}

${ }^{a}$ Number of years required to detect a yearly growth rate $(\lambda)$ of 1.04 .

${ }^{b}$ Number of years required to detect a doubling of the overall population size

${ }^{\mathrm{c}}$ Number of years required to detect a halving of the overall population size 


\section{Table 5 (on next page)}

\section{Encounter rates.}

Mean and standard deviation of encounter rates (number of GPS locations considered captures / total number of GPS locations) for all bears in the sampling period, for 5 grid and targeted sampling configurations, with traps stationary or moved between capture sessions ( $N=42$ bears, with 30 simulations for each configuration). 
Table 5

\begin{tabular}{lcclll}
\hline & \multicolumn{2}{c}{ Stationary } & & \multicolumn{2}{c}{ Moved } \\
\cline { 2 - 3 } \cline { 5 - 6 } & $\bar{X}$ & & & \\
& & & & \\
& & & & \\
Configuration & & & & & \\
& & & & & \\
\hline $49 \mathrm{~km}^{2}$ grid & 0.03 & 0.01 & & 0.03 & 0.00 \\
$81 \mathrm{~km}^{2}$ grid & 0.02 & 0.01 & & 0.02 & 0.00 \\
$121 \mathrm{~km}^{2}$ grid & 0.01 & 0.01 & & 0.01 & 0.00 \\
Targeted & 0.12 & 0.03 & & 0.12 & 0.01 \\
Targeted (1/2) & 0.06 & 0.02 & & 0.06 & 0.01 \\
& & & & & \\
\hline
\end{tabular}

${ }^{\mathrm{a}}$ Encounter rates 


\section{Table 6 (on next page)}

Comparison of capture probabilities.

Mean and standard deviation of capture probabilities for 5 sampling configurations. We used a $t$-test to compare capture probabilities. 
Table 6

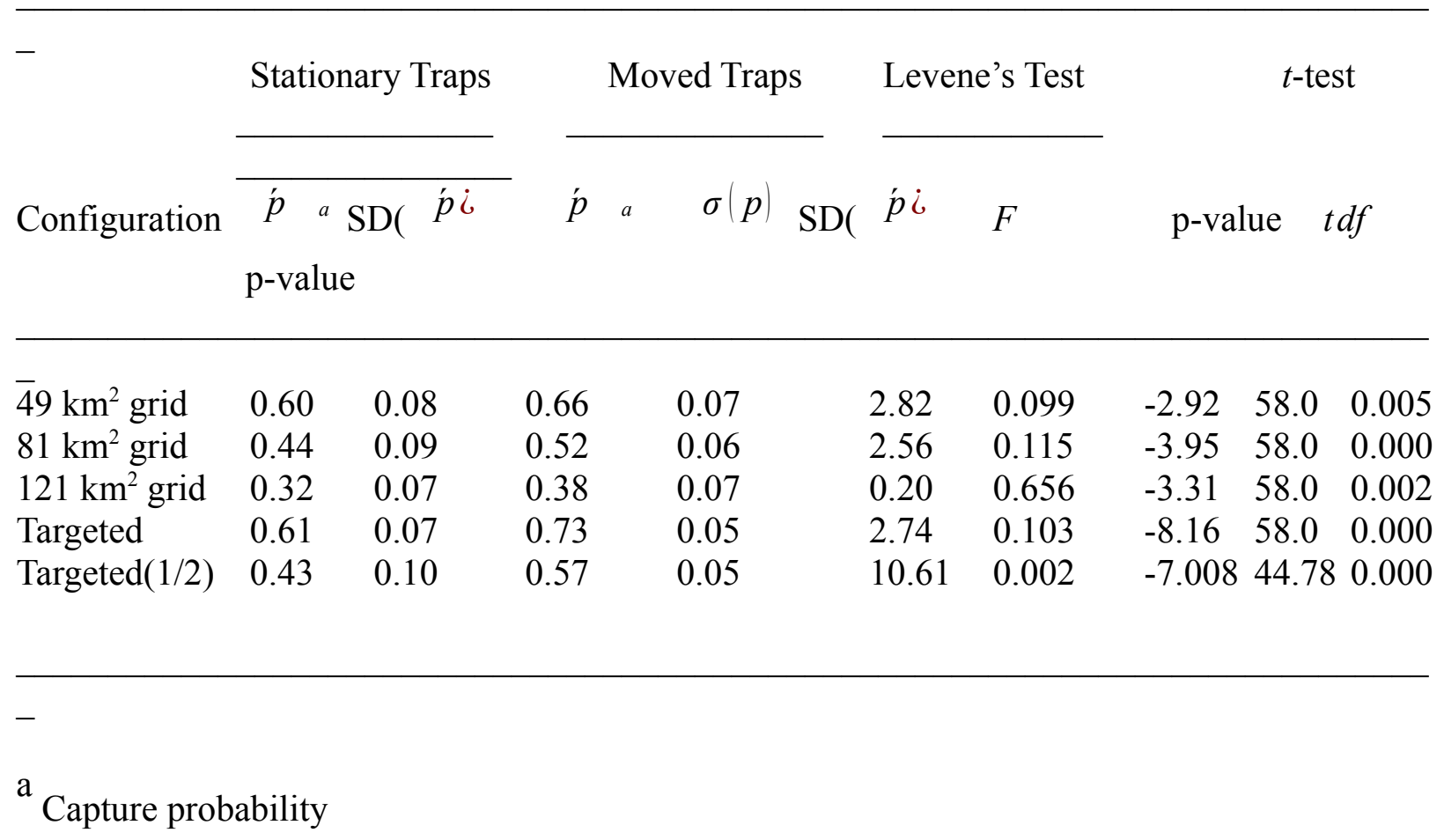




\section{Table 7 (on next page) \\ Comparison of recapture probabilities.}

Mean and standard deviation of recapture probabilities for 5 sampling configurations. We used a $t$-test to compare recapture probabilities. 
Table 7

\begin{tabular}{|c|c|c|c|c|c|c|c|c|}
\hline \multirow{3}{*}{ Configuration } & \multicolumn{2}{|c|}{ Stationary } & \multicolumn{2}{|c|}{ Moved } & \multicolumn{2}{|c|}{ Levene's Test } & \multirow[b]{2}{*}{$F$} & \multirow{2}{*}{$\begin{array}{l}t \text {-test } \\
\text { p-value }\end{array}$} \\
\hline & $\dot{c}^{a}$ & $\bar{c}_{R}$ & \multicolumn{2}{|c|}{$\operatorname{SD}\left({ }^{\prime}\right)$} & $\dot{c}^{a}$ & $\mathrm{SD}\left({ }^{\prime}{ }^{\prime}\right.$ & & \\
\hline & $t$ & $d f$ & \multicolumn{2}{|c|}{$\mathrm{p}$-value } & & & & \\
\hline \multirow[t]{2}{*}{$\overline{4} 9 \mathrm{~km}^{2}$ grid } & 0.47 & 0.13 & 0.43 & 0.08 & 4.05 & 0.049 & 1.19 & 49.17 \\
\hline & 0.241 & & & & & & & \\
\hline \multirow[t]{2}{*}{$81 \mathrm{~km}^{2}$ grid } & 0.42 & 0.12 & 0.34 & 0.10 & 0.11 & 0.747 & 2.79 & 58.0 \\
\hline & 0.007 & & & & & & & \\
\hline \multirow[t]{2}{*}{$121 \mathrm{~km}^{2}$ grid } & 0.48 & 0.10 & 0.29 & 0.10 & 0.01 & 0.934 & 7.36 & 58.0 \\
\hline & 0.000 & & & & & & & \\
\hline \multirow[t]{2}{*}{ Targeted } & 0.75 & 0.08 & 0.69 & 0.06 & 1.48 & 0.230 & 3.73 & 58.0 \\
\hline & 0.000 & & & & & & & \\
\hline \multirow[t]{2}{*}{ Targeted(1/2) } & 0.70 & 0.09 & 0.53 & 0.08 & 0.17 & 0.678 & 7.52 & 58.0 \\
\hline & 0.000 & & & & & & & \\
\hline
\end{tabular}




\section{Figure 1}

Study Location.

We simulated and compared capture-mark-recapture using grid-based and targeted sampling designs for brown bears (Ursus acrtos) inhabiting theKenai Peninsula (center, with elevation shaded from low [light gray] to high [black]), south-central Alaska, USA (inset). The gridbased design used cells with an area of $49 \mathrm{~km} 2,81 \mathrm{~km} 2$ (pictured in gray), and $121 \mathrm{~km} 2$. The targeted design sampled places where important biological resources concentrated the target species (i.e. bear's attraction to anadromous streams; black lines). 


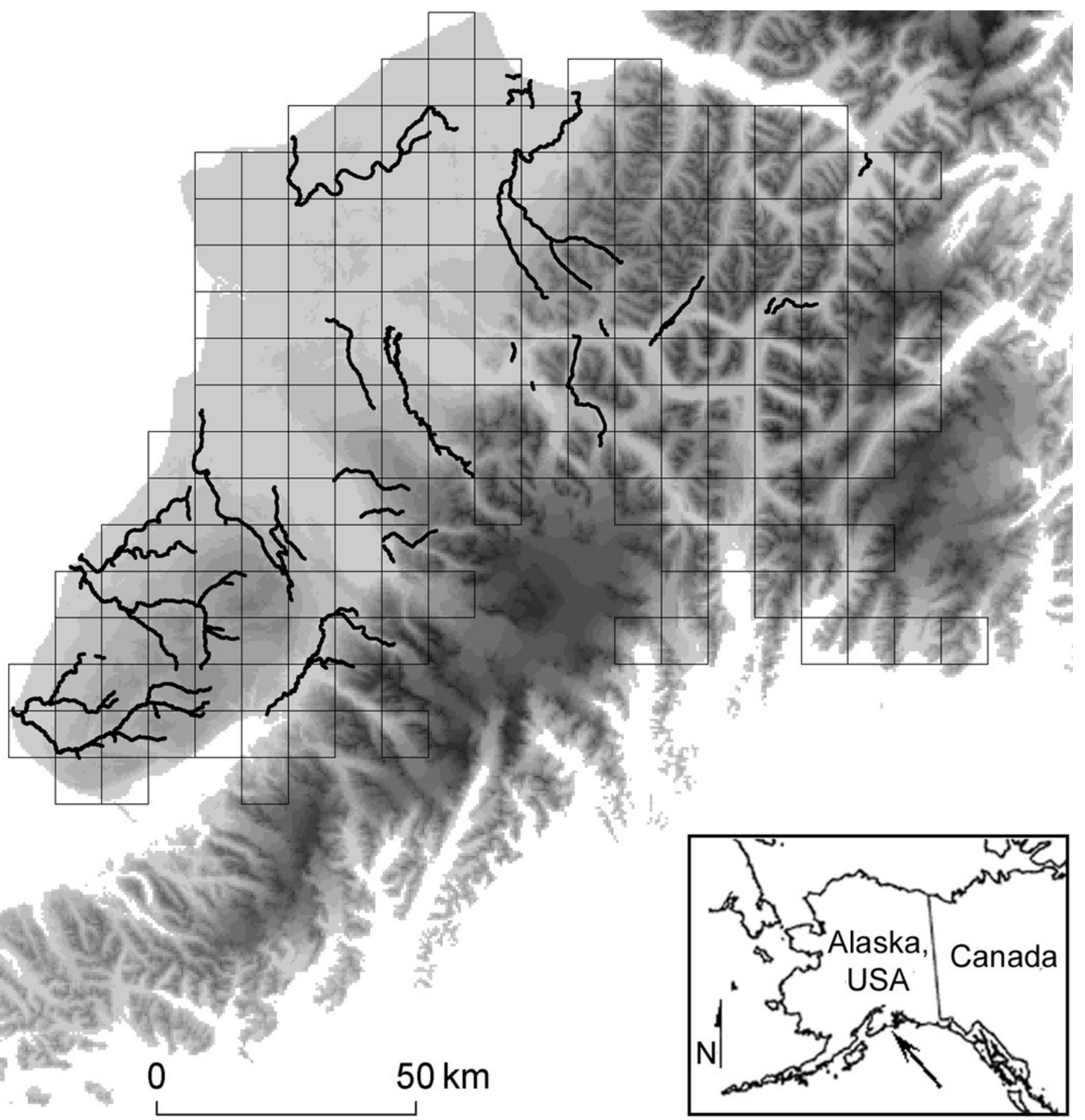




\section{Figure 2}

Brown bear home range sizes.

Distribution of home range sizes of brown bears $(n=42)$ during 1 June through 20 July on the Kenai Peninsula, south-central Alaska, USA. Mean home range size (M) was $149.6 \mathrm{~km} 2$ $(S D=149.7 \mathrm{~km} 2)$. Sixty-seven percent of bears had home ranges smaller than the mean.

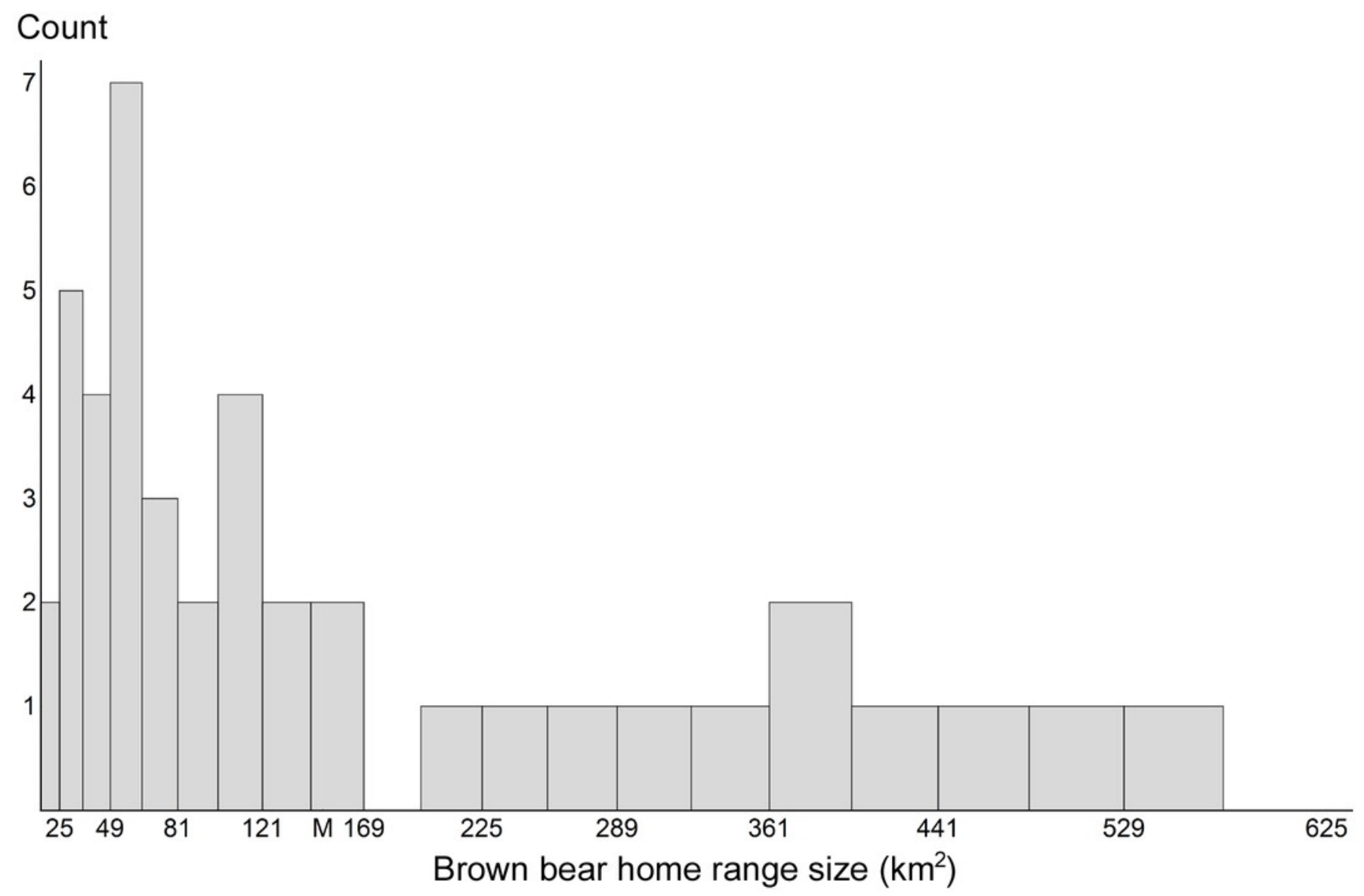

